\title{
Understanding Adaptation to First Episode Psychosis Through the Creation of Images
}

\author{
Angelica Attard ${ }^{1} \cdot$ Michael Larkin $^{2} \cdot$ Zoë Boden $^{3} \cdot$ Christopher Jackson $^{4}$
}

Received: 21 December 2016/Accepted: 11 March 2017/Published online: 17 April 2017

(C) The Author(s) 2017. This article is an open access publication

\begin{abstract}
This article aims to understand and explore the meaning of adaptation to First Episode Psychosis (FEP). An innovative method of data collection was used with ten participants who experienced FEP which integrated drawings of their lived experience within semi-structured interviews. The data were analysed through Interpretative Phenomenological Analysis and hermeneutic-phenomenological image analysis. Participants' experience was captured in four superordinate themes which identified that adaptation to FEP entailed: 'Finding out how psychosis fits into my story', 'Breaking free from psychosis', 'Fighting my way through psychosis', and 'Finding a new way of being 'me'. The participants' path of adaptation to FEP was an interplay of pains, challenges, and gains, and there was resonance with posttraumatic growth in their accounts. This article illustrates that creating images may offer a
\end{abstract}

Angelica Attard

angelica.attard@gmail.com

Michael Larkin

m.larkin@aston.ac.uk

Zoë Boden

bodenz@1sbu.ac.uk

Christopher Jackson

christopher.jackson@bch.nhs.uk

1 School of Psychology, University of Birmingham, Edgbaston, Birmingham B15 2TT, UK

2 Aston University, Birmingham B4 7ET, UK

3 Division of Psychology, School of Applied Sciences, London Southbank University, London SE1 OAA, UK

4 Forward Thinking Birmingham, Finch Road Primary Care Centre, Birmingham B19 1HS, UK powerful way of conveying the multifaceted aspects of adaptation to FEP and could help individuals in communicating and processing their experience.

Keywords First episode psychosis · Adaptation · Art · Posttraumatic growth $\cdot$ Visual methods

\section{Introduction}

'Psychosis' is a primary feature of mental health problems, such as schizophrenia and schizoaffective disorder, which are on the schizophrenia spectrum [1, 2]. In the National Health Service (NHS), people aged 14-35 years experiencing a First Episode of Psychosis (FEP) are usually referred to specialist Early Intervention Services (EIS) where they are supported for the following three years, throughout the 'critical period' which can define the course of the disorder [3]. EIS are fundamental in preventing relapse and the development of severe and enduring mental health problems [4].

Psychosis results in multiple losses of reality, identity, hope, security, and relationships [5-8]. The experience and reoccurrence of psychosis is associated with the development of posttraumatic stress disorder (PTSD) due to the traumatic impact of psychotic symptoms, medication side effects, and hospital admissions [9]. Even in the absence of an official PTSD diagnosis, an initial episode of psychosis can be experienced as traumatic [8], even beyond the acute psychotic episodes [5]. This trauma and loss is especially problematic as FEP typically occurs during late adolescence or early adulthood, disrupting psychosocial development, identity formation, independence, and relationships [10]. Supporting individuals as they adapt to psychosis is therefore particularly important. 


\section{Recovery and Adaptation}

Traditionally, recovery from psychosis meant 'clinical recovery' [11], entailing treatment compliance, psychotic symptom reduction, and the restoration of previous levels of functioning [12] Individuals were positioned as passive recipients [13] and psychosocial aspects of recovery were neglected $[12,14]$. An expanded view of 'personal recovery' developed as service users started to speak openly about their experiences [15]. Through personal recovery, individuals search for new meanings and purposes in their life and experience growth, despite ongoing symptoms and secondary consequences, such as stigma [16]. Personal recovery is achieved as individuals rebuild their life and identity, regaining what they had lost $[6,7]$. This recovery is multidimensional [16], with different aspects of symptomatic, social, functional, and psychological recovery occurring, to varying degrees [17].

One way to understand how individuals adapt to FEP is through turning to the trauma literature [18]. According to the theory of shattered assumptions [19], trauma can crush individuals' original views of themselves and the world, requiring the individual to re-evaluate and build new, more resistant beliefs, which accommodate the trauma and its possible re-occurrence. Psychological adaptation to psychosis can similarly involve forming new, helpful constructs of oneself and the world [18], rendering the concept of posttraumatic growth (PTG) relevant for people with psychosis. PTG is the positive psychological change which some people experience even as they deal with trauma [20]. Growth can occur in five domains; people may appreciate life more, identify new opportunities, feel internally stronger, develop closer relationships, and experience spiritual renewal [20]. These positive outcomes have been seen to form part of people's recovery experiences in psychosis [21, 22].

\section{The Present Article: Learning From Experience}

Further exploration into PTG can balance the traditional focus on negative aspects of trauma [23] with comprehension of recovery after FEP [24]. This is clinically pertinent because the NHS emphasises recovery-focused, person-centred care, which aims to enhance individuals' well-being, quality of life, coping abilities, relationships, and life goals [25]. Understanding adaptation to psychosis can help professionals to support service users through the distressing and constructive aspects of adaptation. People with FEP may feel more hopeful about recovery [17] and learning how to secure this hope throughout the process of adaptation is important during the critical period [26]. This study aims to gain insight into individuals' experience of adaptation to FEP and to explore the relevance of 'growth' as part of their adaptation. To do this, an experiential qualitative approach was taken. In many previous qualitative studies of early psychosis (e.g. [7]), young adults have provided important insights into their experiences. However, this has occurred within the constraints of interview data which may be more concrete and less elaborative than might be expected in qualitative research. This raises the question of whether the constraints of language enable individuals to convey the more nuanced and difficult-toarticulate aspects of the complex lived experience of psychosis. To support exploration of this we have adopted an innovative method of data collection which integrates participant-created drawings within semi-structured interviews. Drawings can be used to initiate verbal exploration and also to act as independent sources of meaning. Morrison et al. [27] suggested that people with psychosis often experience intrusive visual images about their symptoms of psychosis as well as their traumatic life experiences. The use of visual methods may enable expression of such imagery and provide important insight into individuals' experience.

We adopt a hermeneutic phenomenological approach to both text and image, within the established tradition of Interpretative Phenomenological Analysis (IPA), a method that enables researchers to obtain an in-depth understanding of participants' personal meaning-making [28]. In our approach, we examine the image content, its verbalisation, its production, and the meaning it conveys for participants and researchers [29, 30].

Previous research with a similar population has used another visual method, photo-elicitation, which was experienced positively by participants [31]. To our knowledge, drawings have not been used as a research method with this population before. However, art therapy research has shown that art can enable safe emotional expression and be a non-verbal and non-threatening means of communication for people with psychosis [32-35]. The richness of drawings combined with verbal exploration can provide deep insight into participants' experience [29, 36, 37].

\section{Method}

\section{Participants}

Participants were recruited through purposive sampling from an EIS in the NHS. To ensure a degree of homogeneity, participants were young adults (18-35 years old) and had experienced a first psychotic episode which led to a referral to the EIS. They were recruited between nine months following their psychosis, at which time positive psychotic symptoms are expected to have ameliorated with antipsychotic medication [38], and up to 36 months after. 
This is considered the 'critical period' for EIS intervention. Participants were excluded if they were actively suicidal, experiencing acute psychosis, or not English-speaking. Full ethical approval was granted by an NHS ethics review board. Approximately 56 people from the team caseload met the inclusion and exclusion criteria. Out of these, it was clinically decided that 33 could be approached about the research by their care coordinators. Eleven people expressed an interest in participating. Subsequently, the first author met with them to discuss the research rationale and process, and to re-assess their eligibility to participate. Ten of them provided verbal and written informed consent to participate and one person decided not to participate, but did not give clear reasons for this. Reasons for refusal to participate were invited, but only on a voluntary basis. There were four women and six men, aged 19-35 years (mean $=26$ years). Participants came from various ethnic backgrounds, with the majority being White British and Asian. Participants had been with the EIS from 9 months to 3 years $($ mean $=18 \mathrm{~m})$. Information on participants' demographics is summarised in Table 1 .

\section{Data Collection}

A service user research group was consulted on the appropriateness and sensitivity of the research design and process. The first author conducted one-off semi-structured interviews with the participants, lasting 90 minutes on average. The interview schedule was developed and adapted from that used by Boden and Eatough [29], and was divided into three stages:

1. Expression: Participants were asked to briefly describe the initial occurrence of their FEP to help them engage with their experience at that time. They were then asked to create an image that illustrated the effect FEP had on them and their lives. This aimed to get closer to their adaptation experience. Participants were given a selection of papers of different sizes and colours and art media including pencils, biros, coloured pencils, felt-tip markers, chalk pastels, oil pastels, and acrylic paint. Notes were taken on how participants approached the activity.

2. Mapping: Once the participants fully completed their drawing, they were guided to describe parts of the drawing, the overall meaning, and the process they went through as they drew. This illuminated the meaning of the image for the individual [30, 39].

3. Verbal Exploration: Participants were asked further questions regarding the meaning of FEP, its impact, and their adaptation such as, 'at the time how did you make sense of what was happening?' and 'how have you responded to your experience?'. These were open, reflexive, and flexible questions to allow participants to freely explore their experiences. The image remained a point of reference throughout the interview.

Some previous research has indicated that research participants may be reluctant to draw [36, 40, 41], therefore the purpose of the drawing was carefully explained [30]. Consideration was given to anonymity and the ownership of the drawings. Rose [42] argues that drawings are no different to text-based data in this respect, and therefore we digitally blurred one of the images (a self-portrait) to ensure anonymity. Images were electronically copied and participants were able to keep the originals. Interviews were audio-recorded and transcribed verbatim. Pseudonyms were used and identifiable information in the data was anonymised or concealed. The first author kept a reflexive journal to critically consider any preconceptions during data collection, analysis [43], and image interpretation [39]. She acknowledges herself as a passionate artist who believes in the use of art as a means of exploration and communication. After completion of the study, a summary of the results was disseminated to participants and a presentation provided to the participating EIS. The images were published with participants' permission.

\section{Data Analysis}

The study took an expanded phenomenologicalhermeneutic approach, similar to that used in Boden and Eatough [29]. This adapts IPA [43] to incorporate analysis of the drawings. IPA is underpinned by phenomenology, which aims to develop a rich understanding of how people make sense of their lived experience of a phenomenon [43]. It is concerned with in-depth analysis of the idiographic experience of particular individuals and does not aim to make general claims about the causes of events [28]. Individuals' description of phenomena is interpretative and influenced by their relationships and circumstances [44]. IPA is also hermeneutic as it values both participants' and researchers' meaning-making [43]. Boden and Eatough [29] suggest that multimodal approaches to research can expand our understanding of experiential phenomena. Images produce meaning about life experiences [29, 36] and the metaphors they incorporate may extend beyond the constraints of language [45]. Images are a source of interpretation. Like text, they reflect a version of reality created by individuals that is then interpreted by researchers through an expanded hermeneutic phenomenology [45].

Transcripts and images were analysed together. Initially there was a process of familiarisation with the verbal data [28], then by working case-by-case through 'free coding', initial annotations were made to capture what stood out and 


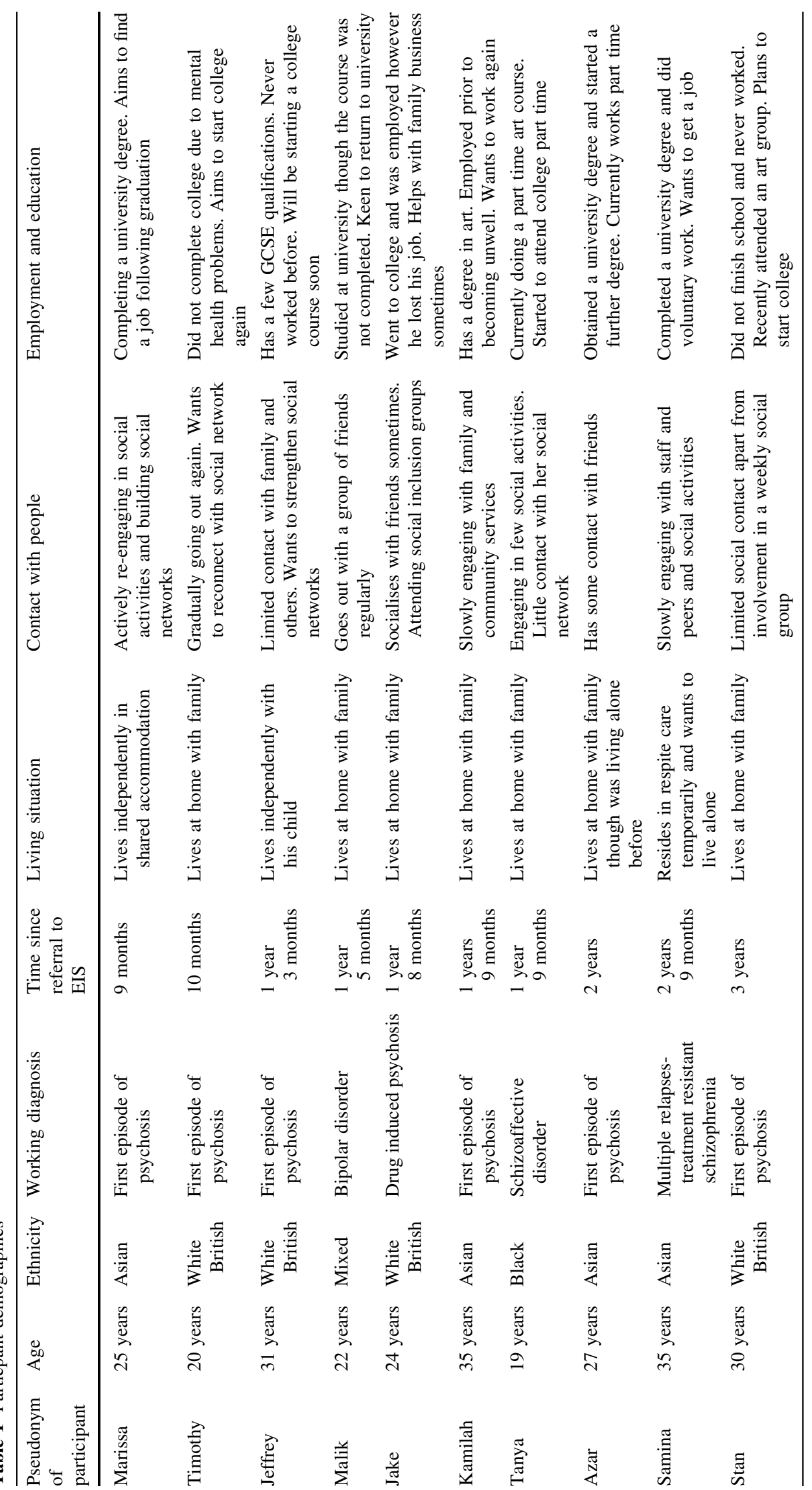


to highlight any preconceptions [44]. Transcripts were then re-read, and descriptive and experiential comments about the objects of concern and their meaning for participants were made, paying attention to language, narratives, and metaphors. The data were then re-analysed with a more interpretative stance. Drawings were analysed using the frameworks described in Boden and Eatough [29], which firstly considered criteria related to the content of the drawing, such as its composition and texture, and secondly, criteria on how the drawing was produced, such as speed of production (see "Appendix" Table 2). Descriptors were written for all criteria after which interpretative comments of the image were added. The transcript and image analyses were combined, and codes of meaning were grouped into emergent themes. These were sometimes derived directly from the drawings and their metaphors (see [40]). Once this was completed for each transcript, emergent themes were then clustered into superordinate and subordinate themes. A corresponding image was identified for each superordinate theme based on which image best captured the 'essence' of all the subordinate themes. An interpretative analysis of these four main images was derived from the verbal and visual analysis and presented with each main image.

\section{Findings}

The analysis elicited four superordinate themes, each with subordinate themes and a main image that corresponded to the superordinate theme. The main images were included at the end of superordinate theme with an interpretative analysis.

\section{Figuring Out How Psychosis Fits into My Story}

This theme highlights participants' attempts to make sense of, and come to terms with, both the positive and negative place psychosis had in their life. There are three sub-themes:

\section{What's Going On? I Mean, That's Not Possible, it Doesn't Compute}

Most participants were hit so suddenly by psychosis that it cast a shadow of confusion. Some were unable to remember what happened during psychosis. Tanya illustrated this in her image; she drew 'squiggles' that represented her memory loss and she drew a self-portrait looking back at 'psychosis' as she tried to remember.

Additionally, four participants were confused because they experienced psychosis so vividly that it felt like their reality. They consequently found it difficult to disentangle what was real from what was not as Malik described:
I thought everything was real, everything that I said was real and thought was real. Simple as that. Even if it wasn't real, I thought it was. I was hallucinating." (Malik)

Psychosis was deceptive as some were shocked by the realisation that their psychotic experiences were not 'real' or common experiences for others. This deception was conveyed in the title of Marissa's image: 'Mirror'. Marissa drew a 'world of darkness' to illustrate her experience of acute psychosis and a perfect 'world of light' to reflect her experience after psychosis. Just as one sees their reality when looking in a mirror, Marissa believed both worlds in her image to be real. She now realised that neither were true and both were actually reflections in a distorted 'mirror'.

\section{It's Important to Me Because it's Part of My Story}

Due to this confusion, all the participants attempted to understand what psychosis meant for them and their trajectory through life. Most had conflicted internal beliefs about this. Four reflected on how psychosis changed the course of their life; with this came a tone of grief for the life they could have had, as Jeffrey stated:

I'd probably already been in college by now and I probably already would have got my qualifications, I could have been working and everything. So it probably has held me back. (Jeffrey)

The minority ascertained that psychosis made little or no major difference to them and their lives. Others found it difficult to come to terms with psychosis due to its significant impact. Azar illustrated this by drawing a storm as a metaphor for psychosis. He also depicted bad weather following the peak of the storm, to represent the difficult period of coming to terms with psychosis.

Six people, including Azar, eventually reached a level of acceptance that they had experienced FEP. Samina was the only person unable to accept this. Her anger towards psychosis and the suffering it caused her was shown in the darker, rough scribbles in her image which were pressed hard across the page (Fig. 1).

Marissa, Stan, and Timothy accepted that both the difficult and beneficial aspects of psychosis were an integral part of who they are:

It's just what it is...I got three voices that are mainly my life. I just wish that me and this Steve guy (one of the voices) gets on, you know, but what can you do? (Stan)

Six participants also accepted that they were vulnerable to psychosis and with this came an uncertainty of the future and fear of relapse. Participants learnt that they needed to 


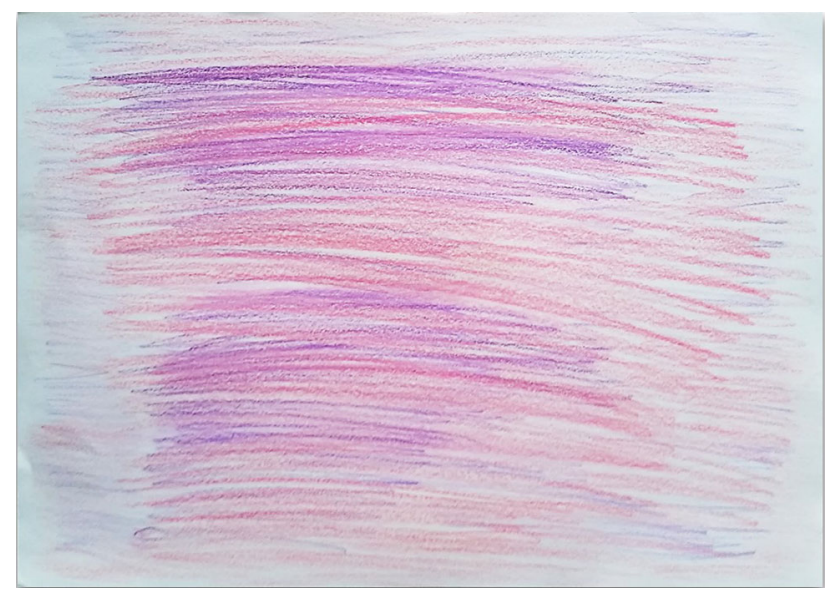

Fig. 1 Samina's image

keep an 'active eye' on themselves. This lingering presence of psychosis was evident in Marissa's image. In the 'world of darkness', she drew an open eye, which signified that psychosis was active, and she drew a closed, inactive eye in the 'world of light'. The link between the eyes represented the possibility that the eye may open and that the realm of psychosis may become visible again.

\section{You've Gotta Know the Bad Side to Get Good}

Six participants expressed that although psychosis was distressing, they were glad it happened, otherwise they may have been stuck in their old life or in a worse position. Through psychosis, they gained insight, support, grew as individuals, and did things they were unable to do before, as described below:

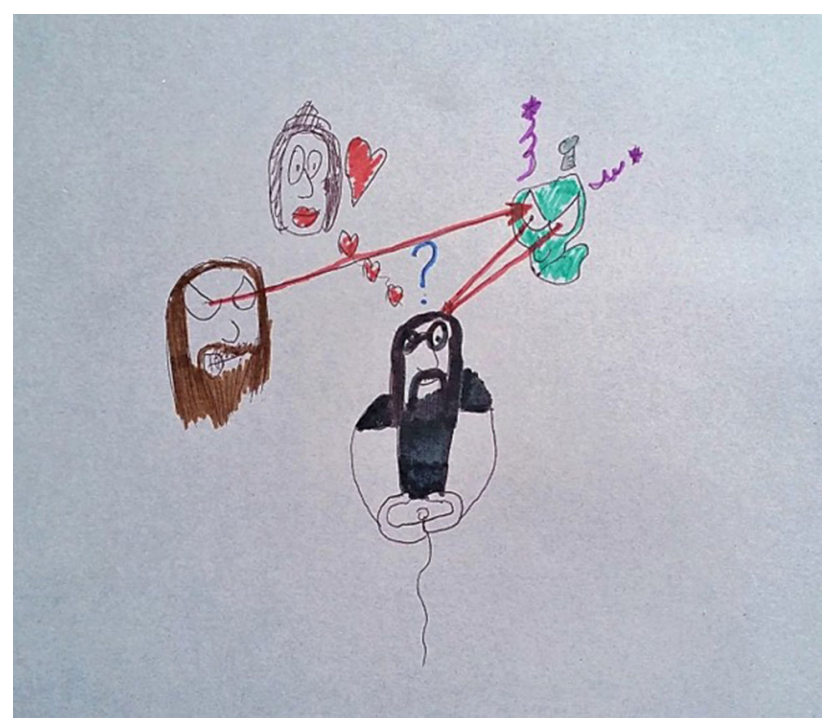

Fig. 2 Stan's image
I wish things were different. I've always wished that I didn't go through it but in the same way I had to go through it, it was not a choice. I had to experience it so I think it's for the better that I did because now I'm on the right path. (Timothy)

Stan emphasised that through psychosis he gained the company of his 'good voices', whom he would miss if they disappeared; he felt affection for the female voice and felt protected by the male voice who guarded him from the 'bad, alien voice', through laser stares (Fig. 2).

This superordinate theme indicated that understanding psychosis was complex as participants oscillated between feelings of confusion, indifference, rejection and acceptance of psychosis. The essence of this theme can be captured in Tanya's image (see Fig. 3) (Box 1).

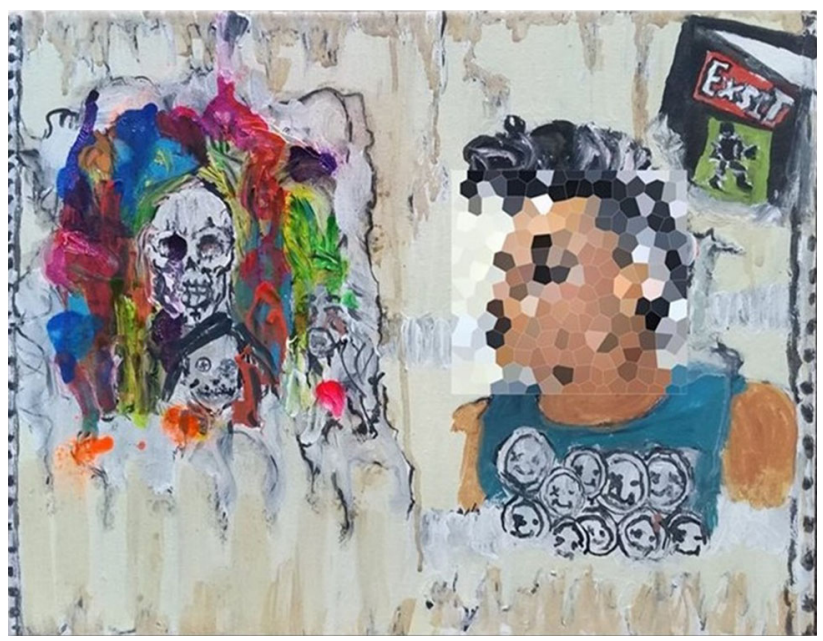

Fig. 3 Tanya's image

Box 1 Analysis of Tanya's image (Fig. 3)

Tanya describes her painting as a depiction of where she was and where she is now. On the left, she paints 'psychosis'. The largest skull represents the darkness of psychosis which is "a force trying to pull me in". Its darkness extinguishes the merging colours which represent the brightness of her life. The smaller skull has a stitched up mouth indicating how Tanya was silenced by psychosis. Another face with wide-open eyes exudes distress, loneliness, and shock. Dark memories about psychosis were triggered for Tanya as she drew, making the image production difficult initially. The image is framed in movie tapes because for Tanya, psychosis feels like an episode in the movie of her life. This episode however disappears from her memory as quickly as it comes. The backdrop is characterised by 'squiggly' shapes which represent her lack of memory and the damage caused by psychosis. Tanya purposely leaves the image title-less to convey the puzzling nature of psychosis to the viewer. On the right, Tanya paints a selfportrait that looks at psychosis. Psychosis is now a picture frozen in time that she can view from a safer distance with fascination. She describes psychosis as a puzzle for which she seeks the missing pieces, whilst she moves towards the light in the edged-open exit door, away from the darkness. Tanya notices her spelling mistake in the word 'Exit' though curiously does not change it. She wants to move on by going through the 'Exist' door so that she can 'Exist' freely 


\section{Breaking Free From Psychosis}

This superordinate theme has three subthemes, which highlight participants' sense of entrapment in psychosis, and their vital transition to breaking free from its restrictions.

\section{Stuck in My Own Mind and Kind of in a Dark Place}

Psychosis resonated with a nightmare that rendered participants powerless and helpless. They all portrayed psychosis as horrible, unsafe, and frightening, and characterised it as 'aggressive', 'rough', and 'evil'. Participants did not want to get caught in psychosis, however its strength and force was not easily resisted, as Azar explored through his image:

Everything is going on really fast and you kind of get caught up in the storm. It's quite an aggressive, attacking kind of storm. Em, it's scary, like worrying, and then I've got myself drowning in no direction as well. (Azar)

The vivid images in this metaphor conveyed how psychosis showed little mercy. Participants felt stuck or trapped in psychosis where everything meaningful came to a halt. The entrapment was psychological because participants felt emotionally numb and disconnected from relationships. Tanya and Kamilah depicted being silenced by psychosis through the image of a skull with a stitched up mouth, and a face with a crossed out mouth, respectively. Participants also experienced a physical entrapment because they were unable to complete day-to-day activities or pursue goals. This was powerfully conveyed in Kamilah's self-portrait chained to her bed and imprisoned behind bars, from which she could not escape.

\section{It's Up to Me to Help Myself}

Most participants described their attempt to break free from this entrapment by taking action and responsibility for their life and health. Participants regained control and avoided relapse by taking medication, following a routine, engaging in previous activities, and talking to family and the EIS. Malik and Kamilha specifically drew these responsibilities in their image (Fig. 4).

Malik drew a staircase where each step represented a responsibility. Starting from the left side of the image, these steps included taking medication, sleeping, eating and drinking, and following orders of what to do. Adherence to each responsibility was his main means of managing psychosis and gaining his freedom. He represented his freedom through a cart on the final step on the right, on which he hoped to ride away.

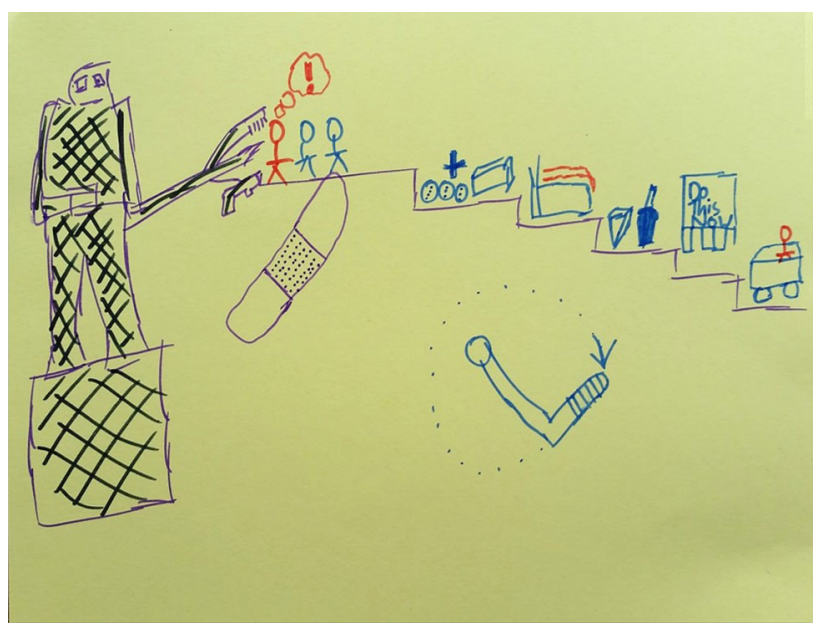

Fig. 4 Malik's image

Participants also attempted to move on with their lives by escaping psychosis. Avoidance and not thinking about psychosis was an important coping strategy for some. Escape was represented in Jake's image, which told the story of his attempt to physically escape from the fear and vividness of psychosis by getting onto a train (Fig. 5):

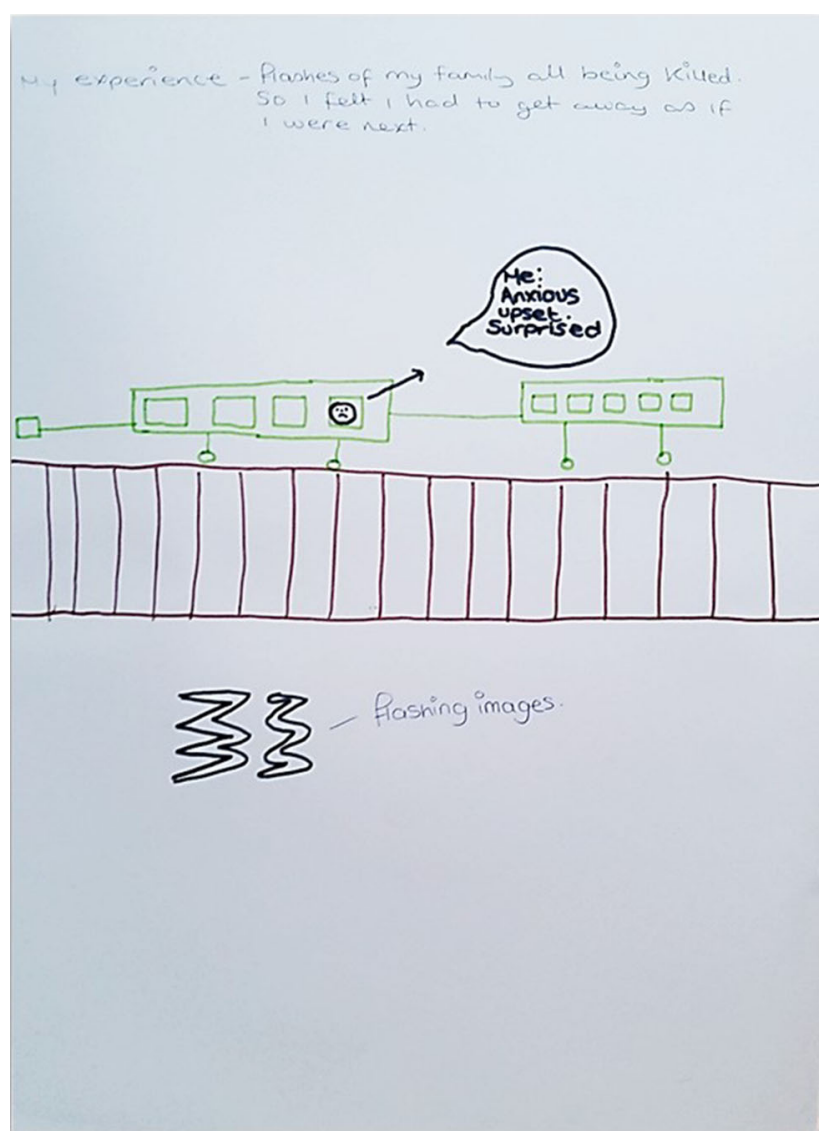

Fig. 5 Jake's image 
Escape was also visually represented in the 'Exit' sign in Tanya's image, and in the softened or lighter edges of Samina's abstract image, which portrayed her main escape route:

There are these areas of softness around the edges.

And to me they just represent the feeling that I just want to sleep all the time, just go to sleep like a baby does...to escape the reality of my life now. (Samina)

Several participants attempted to ignore their symptoms through distraction. This was important for Stan who drew himself playing a computer game to represent his typical attempts to ignore the 'bad' voice in his head.

\section{Getting Back to Normal Routine, Like What I Used to Do}

By facing or escaping from psychosis, several participants started to restore their life and relationships and feel like themselves again. They felt encouraged by positive changes such as increased self-confidence. Timothy described this passionately:

Yeah it's exciting to get your life back really...because before life was just somewhere I didn't want to get to and I can laugh about it now because you know, I'm not there anymore. (Timothy)

The angel in Timothy's image was a symbol of this better life where things were going well, contrary to the devil drawn in his image which represented the time when psychosis took over his life. Participants found it easier to go out and interact. They were reminded of who they were before psychosis and aimed to re-establish their identity and place in society, as Marissa described:

I went to the church and met some people. They accept me and we like each other, we have good conversation, we have good time, they bring me out these people... they bring me back to normal, back to my personality and they're really helpful (Marissa)

This superordinate theme explored participants' transition from a state of mental and physical entrapment, to regaining freedom; this was captured in many aspects of Kamilah's image (Box 2) (Fig. 6).

\section{Fighting My Way Through Psychosis}

The three subthemes in this superordinate theme conveyed the active struggle participants went through as they adapted to FEP, which they were determined to fight through.

\section{That was Quite Challenging}

Getting their identity, life, and relationships back was not easy. Most participants had to push themselves to face their fears and keep themselves on track, and trusting others and

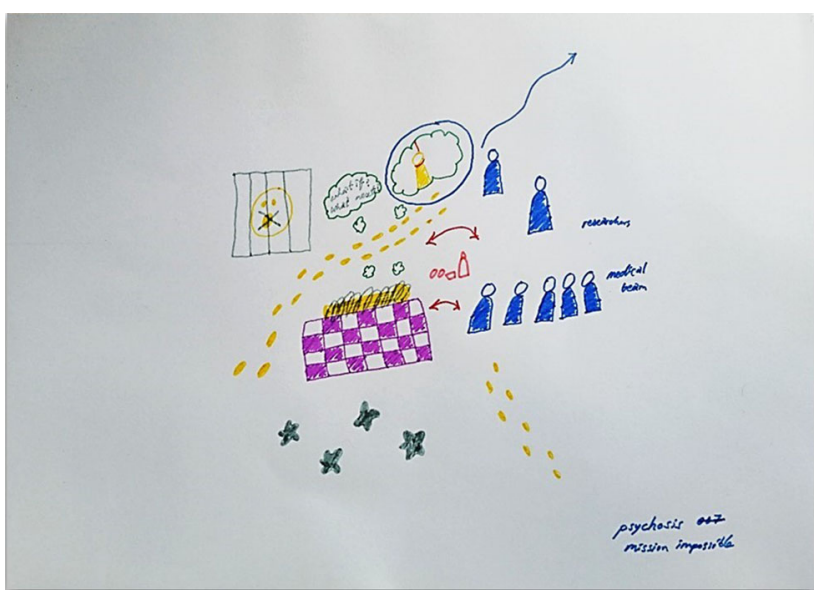

Fig. 6 Kamilah's image

Box 2 Analysis of Kamilah's image (Fig. 6)

Kamilah depicts herself in yellow, chained to her purple bed and enslaved to catastrophising thoughts ("What if? What next?"), which stop her from doing anything including her personal care. She consequently feels dirty, which she symbolises through large grey shapes. Her self-deprecation elicits suicidal ideations, which Kamilah illustrates in a stark sketch of herself hanging. Kamilah draws herself in another scene locked behind bars. This evokes a sense of her mental and physical entrapment, which is enhanced through the rhythm of her yellow footsteps pacing endlessly at home. The arrows indicate Kamilah's active attempts to break free from psychosis as she goes to and fro between both sides of the image. Another set of yellow footsteps, represent her moving away from psychosis to meet medical professionals and researchers. Kamilah draws a bubble and arrow around her suicidal image, indicating her attempt to let go of her suicidal thoughts. The drawing's title, 'Psychosis 007 Mission Impossible', sheds light on the challenge of facing psychosis; the imagery captures Kamilah's sense that she is still engaged in this process. In the centre, is a bottle of medication, which, although small, has a signifcant influence on her getting better. Kamilah purposely portrays herself in yellow which she considers a happy colour that reflects a thread of hope throughout the image

accepting support was difficult. Kamilah described some of these challenges:

...And taking the medication has been challenging for me, like how I react to it. Going out is a challenge and getting up in the mornings is a challenge (laughs). I don't want to get up in the mornings and then I just want my day to be over... I'll feel like the day is going to be a struggle... (Kamilah)

Attempts to escape were not always successful either and required persistence. For instance, Samina stated that the voices disrupted her sleep and thus, hindered her escape. For a few, there was a regimented feel to the activities they had to complete to stay well because stopping them could lead to relapse. Malik drew a black statue which pointed weapons at his self-portrait (the stick-figure in red), in case he did not adhere to his responsibilities, which left him feeling like he had little freedom to choose how he wanted to live. 


\section{There's Quite a Long Way to Go}

Although participants acknowledged feeling better, most knew that it was not over due to ongoing difficulties and not having achieved their goals yet, as Jeffrey stated:

A part of me will have to try to get $100 \%$ cos I'm still not a $100 \%$ now because like I feel better but I still get paranoid. I can't look people in the eyes properly, so there's still a lot of work that needs to be done. (Jeffrey)

The hurdles were illustrated in Jeffrey's image (see Fig. 7); the unravelling of the spirals showed that things were improving, though this progress was blocked by the ravelling of new spirals:

A few participants acknowledged that their life was constituted of 'ups and downs' and Azar purposely depicted ongoing storminess in his image. Additionally, the ongoing presence of psychotic symptoms prevented some participants from living and reaching their full potential. Stan drew his 'bad voice' attacking his self-portrait through laser stares which caused ongoing distress. Some experienced psychosis as taunting because it did not go away as Samina described:

(Psychosis) it's a burden... it's something I'm carrying around which stops me and inhibits me from living life. (Samina)

\section{Now I'm Getting Better I Feel as Though I can... Possibly Overcome the Fears}

Participants were determined to work through these hurdles, achieve their goals, and strengthen their confidence, even though they knew this would be daunting. Participants' fighting spirit was fuelled by the benefits of getting better and encouragement from themselves and others.

The red arrows in Kamilah's image indicated how she actively fought her way through psychosis, even when it temporarily pulled her back into its abyss. Some felt better

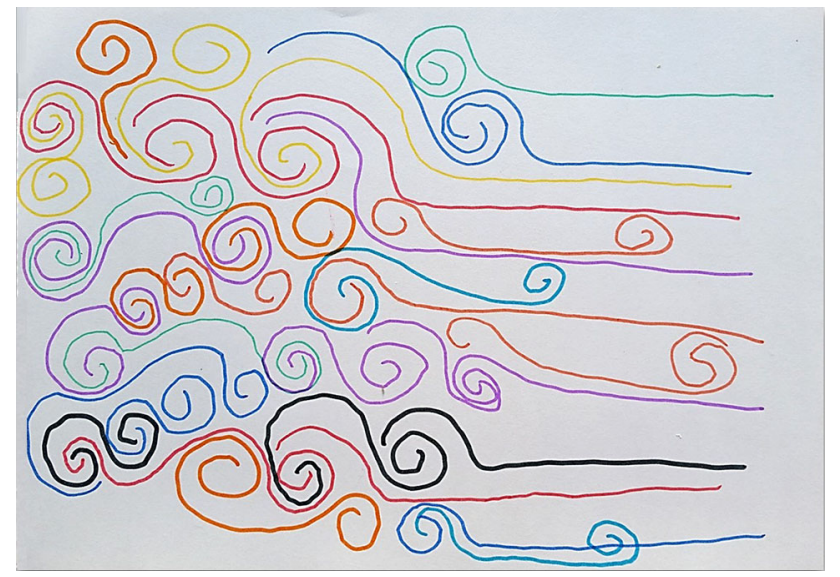

Fig. 7 Jeffrey's image equipped to cope because of their increased coping strategies and support from family or the EIS. This instilled hope and alleviated the pressure on them, as communicated by Timothy:

I'm going to find it hard if I did go back to college. I'm sure I' $m$ going to be nervous and find it quite hard, but I feel as though I've got a much better chance this time round than what I had before. (Timothy)

Half the participants wanted to take things slowly and preferred to focus on their present rather than on future concerns. Overall, this superordinate theme highlighted that adaptation was hard and a work in progress. However, participants' readiness to get better shone through as reflected in Azar's image in Fig. 8 (Box 3):

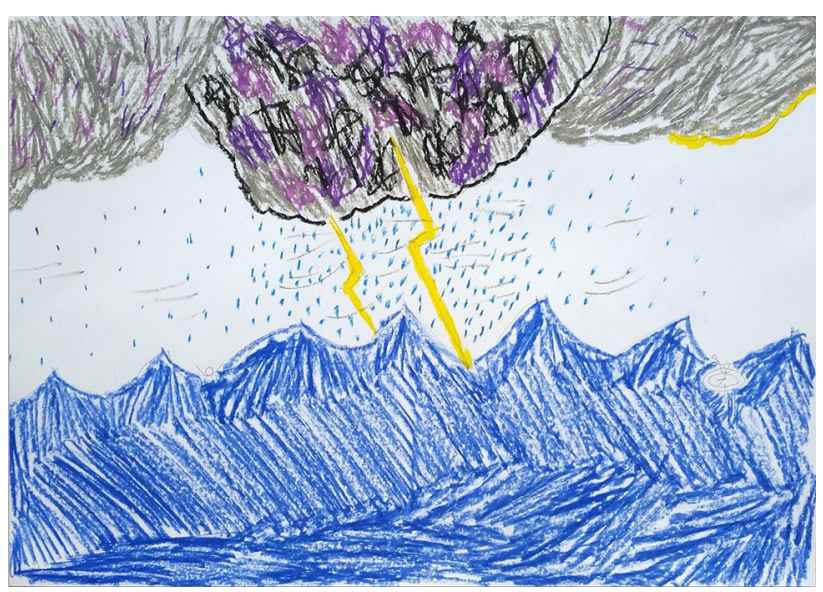

Fig. 8 Azar's image

\section{Box 3 Analysis of Azar's image (Fig. 8)}

From the left to the right side of the image, Azar recounts his ride through psychosis through a metaphor of a storm. Before psychosis, the storm develops as the rain (the blue dots) and wind (the grey lines) increase, until psychosis/the storm reaches its peak in the centre of the image. Psychosis is all-consuming as can be seen in how the storm fills the paper. It is huge compared to Azar's self-portrait which is sketched in pencil and barely noticeable amidst the waves. The aggression of the storm/psychosis reverberates through the rough oil pastel strokes and bold colours in the clouds. The bolts of lightning are blatant and seem merciless. The storm's upheaval reflects the turbulence of Azar's emotions during psychosis and his vulnerability exudes through the storm's dangerous circumstances. The image changes as the storm becomes less aggressive and as Azar starts to get better. Yet, the ongoing rain illustrates the difficult post-psychotic period when Azar comes to terms with what had hit him. On the right, his self-portrait is now seen on a rubber dingy which equips him to cope better. He is not in the midst of the storm/psychosis and can view it from a different perspective as he moves away. The enduring roughness of the sea across the image reflects Azar's uneasy state of mind which he still endeavours to manage. Despite the magnitude of the storm, Azar is coming out the other end and on a dingy. This accentuates his chance of survival now that he has more tools. The sense of hope is emphasised by the cloud's silver lining 


\section{Finding a New Way of Being 'Me'}

This superordinate theme has four subthemes that highlight participants' exploration of their identity, relationships, and the meaning of their life, in light of psychosis.

\section{Feel Like My Personality was Totally Changed}

Most participants lost themselves during the acute stages of psychosis because they no longer recognised their 'psychotic' self. Some felt emotionally labile and realised that their behaviour was out of character. Samina portrayed how her personality became tainted by psychosis through the way her favourite colour (violet) became 'muddied' by the rust colour in her image:

I wanted to reflect who I originally was, the violet, because it's one of my favourite colours and it's gone all sort of muddy with the rust colour, like the experience, what it's done to my personality. (Samina)

Participants' 'self' in relationships also changed as some became introverted and distrusted their closest relationships, as Malik described:

I was having a lot of paranoia so I was accusing family members of doing certain things. If I'd have gone out, then I would have accused my friends of doing certain things which luckily I didn't get to that stage because I was so reclusive I didn't want to go anywhere. (Malik)

This impact of psychosis had led five participants to contemplate or attempt suicide, due to their despair and hopelessness.

\section{You Try to Understand Yourself Much Better than You did Before}

Following psychosis, all the participants actively attempted to understand and reconnect with themselves. Six participants described developing a new sense of self as they acknowledged their strengths and became more self-compassionate. Some, like Azar, became more comfortable with different aspects of their personality.

However, four participants were still re-establishing their identity and self-trust. Whilst they acknowledged their strengths, they were ridden with weakened self-confidence. The words 'what if? what next?' in Kamilah's image indicated how she was plagued by catastrophizing thoughts about whether she can cope. Marissa described feeling stronger following psychosis and simultaneously weaker because she worried more, felt less confident, and could not trust herself and her experiences like before. Marissa subtly drew these perceived weaknesses in her image. Amidst the beauty and luck of the 'world of light', was an imperfection in the way the clover leaves were intentionally drawn detached from their stems.

\section{Realised How Great Life is}

Five participants experienced a new appreciation for life and being alive. They were grateful, or attempted to be grateful, for the things they did not appreciate before psychosis. Marissa communicated how lucky she felt through the colours and clovers in the 'world of light', and Timothy expressed his appreciation at length now that he was on an 'angel path':

I really value having a house, having people understanding, having a good life, because you know, I always think about people who are in like a third world country and yeah who don't have anything. So I really value things ... I think I took things for granted before but I've realised that you know life's short. (Timothy) (Fig. 9)

Participants also wanted to enjoy life more than they did before. Some experienced a new-found excitement and hope for their future, had new aspirations, and wanted to invest in themselves. Marissa and Stan also described experiencing strengthened spirituality following psychosis,

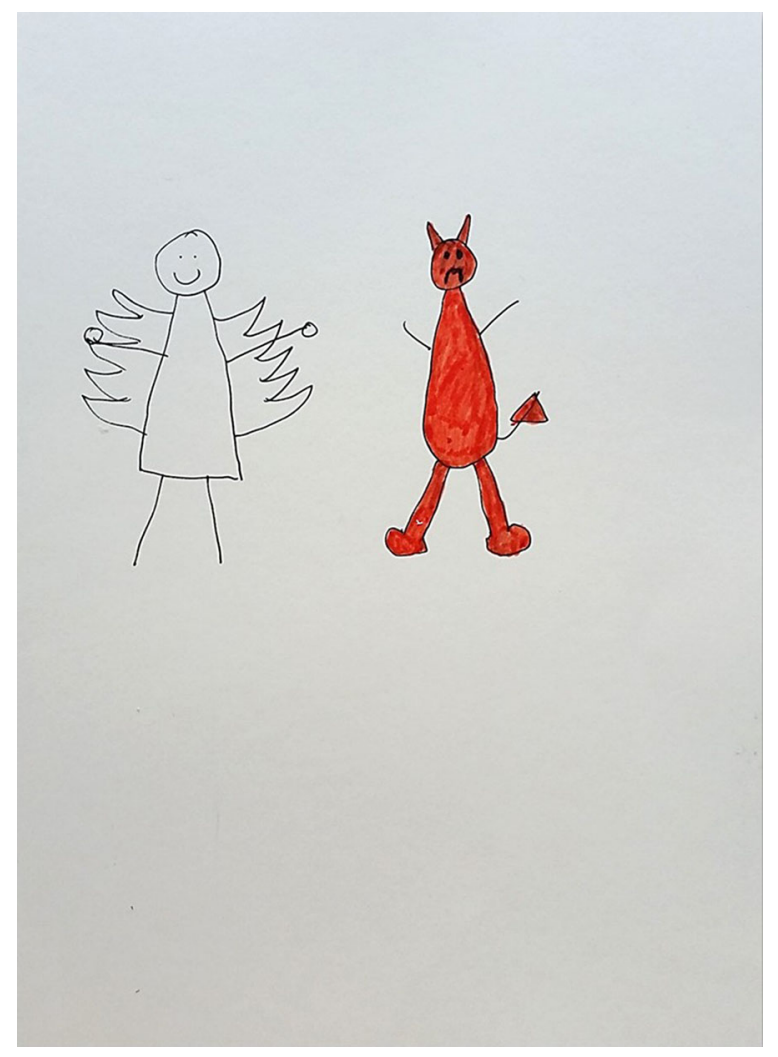

Fig. 9 Timothy's image 
which helped them cope and look towards the future. Conversely, Samina and Malik had no hope for their future or for achieving their life goals. For them, life was about surviving and "existing on a daily basis" as Samina described.

\section{Being Around People and Fitting in}

Psychosis shifted participants' attitude towards others. Six participants increasingly appreciated their family who were unconditionally supportive even at the worst of times. They valued being understood by their family and some believed that psychosis brought their family closer. Participants also highlighted their value for the EIS where they felt understood and supported.

The experience of being different and vulnerable resulted in three participants becoming more compassionate and non-judgemental of others. Additionally, six participants were conscious of how they were perceived now that they had psychosis. A few still felt misunderstood by family, whilst others feared being misunderstood by peers. Participants' history created a stigmatising label that skewed people's view of them and elicited rejection. Jeffrey explored this:

You feel a bit of an outcast and that I suppose don't you? If your family ain't gonna want nothing to do with you, why would anybody else? (Jeffrey)

Marissa and Tanya made active efforts to blend into normality by distancing themselves from peers who knew about psychosis. Interestingly, Stan welcomed the label because psychosis was part of him and he normalised his symptoms.

Marissa's image (Fig. 10) captures the participants' painful and growth-inducing transition to re-establishing their identity, life, and relationships, highlighted in this superordinate theme (Box 4).

\section{Discussion}

This research contributed towards the understanding of adaptation to FEP and this was brought alive through the creation of images. The path of adaptation entailed a complex interplay of losses and gains. Participants attempted to come to terms with the negative impact of FEP and made active efforts to break free from psychosis to reach their goals. Participants experienced positive changes and growth as they developed coping strategies, regained their life, and viewed themselves, their reality, and relationships from new perspectives. Nonetheless, these gains came with pain as participants still grieved for their losses and faced ongoing difficulties on their path of adaptation.

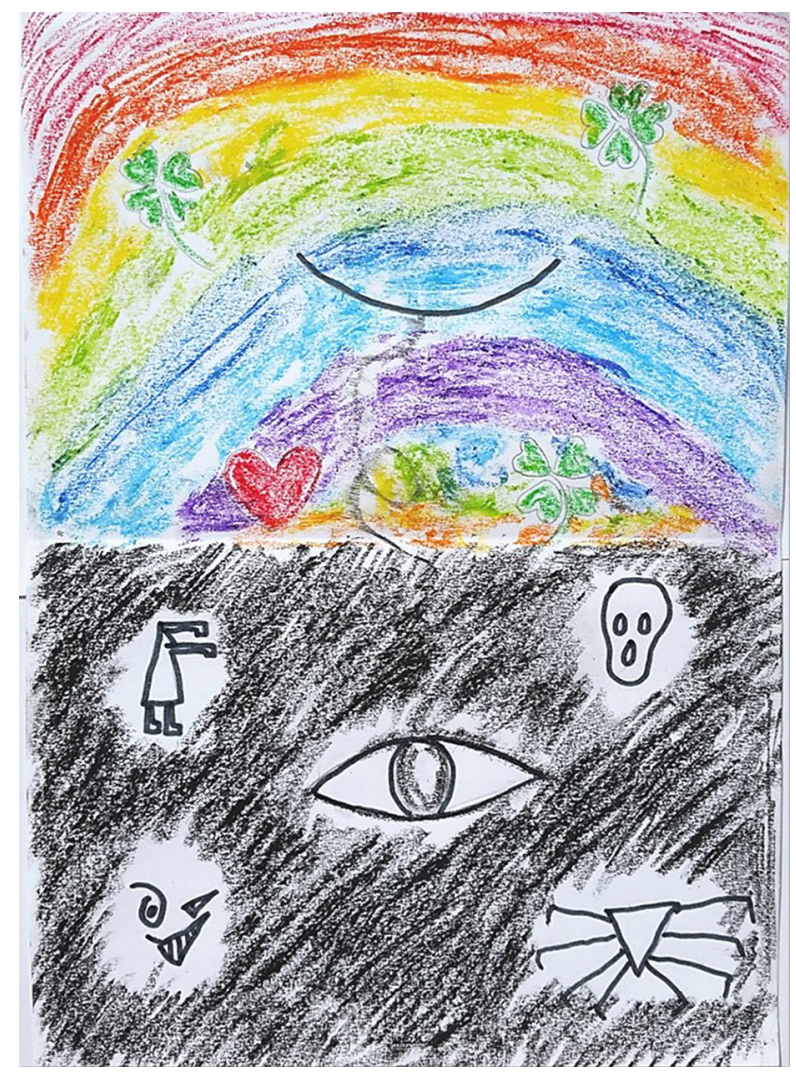

Fig. 10 Marissa's image

Box 4 Analysis of Marissa's drawing (Fig. 10)

Marissa describes psychosis as a double-edged sword. There is a contrast in the colours of the two worlds in her image, though a consistency in their texture and composition, where the eye is the central focus. The dark world was drawn first. The intensity of the eye's gaze reflects Marissa's conviction that she was watched during psychosis. The eye stands out against the harsh black strokes in the background, as do the other elements, making their presence unmistakable. Marissa feels like she lost herself in this world and conveys her fear, lack of safety, and mistrust through fearful images of a vampire, a taunting face, a skull, and a spider. Conversely when the eye is closed, a new world of light is created that is good and beautiful. Marissa illustrates this by using the spectral colours that constitute light when it is shone through a prism. Although the eye is still there, it is closed and its presence is weakened. The fourleafed clovers symbolise how lucky she feels to have support and to be alive. The heart symbolises her increased love for and closer connection with her family, herself and God. Yet, Marissa points out an imperfection in this apparently perfect world; some of the clover leaves are disconnected from their stems. Amidst her gains and strengths, she notices her weakened self-confidence and selftrust. Marissa titles her image 'Mirror'. She initially perceived both worlds to be her reality. She now realises that both are fictitious: one too perfect (a fantasy) and one a nightmare. Although she is not ready to reveal psychosis to others who may not understand, Marissa accepts both worlds to be part of her and her past. Marissa acknowledges that psychosis may be part of her future through a faded black link that connects the closed and open eyes. The reawakening of psychosis elicits in her both fear, and determination that she can overcome it 


\section{Adaptation and Posttraumatic Growth}

The negative experience of acute psychosis was an integral part of participants' narratives. Participants emphasised the distress psychosis elicited, and their consequential loss of control, memory, identity, and sense of trust. These losses concurred with those in McCarthy-Jones et al. [7]. This may explain participants' active search for a coherent explanation for FEP. Participants' oscillation between different explanations throughout the critical period highlights how difficult this search is. Other research also identified that people had alternating explanations for FEP [7] and struggled to make sense of it [46]. In the latter study, this was attributed to FEP being a new and unknown experience.

Zoellner and Maercker [47] considered meaning-making fundamental for psychological adjustment. It influenced people's emotional reaction to psychosis [48], hope for recovery [46], and search for identity [7]. In this research, it also influenced participants' willingness to take responsibility for their life. Self-responsibility has been deemed a core aspect of recovery [49] that helps individuals to feel empowered. Stewart and Wheeler [50] and Frankl [51] suggested that responsibility is the essence of being and it enables individuals to face life challenges. Most participants made courageous attempts to take responsibility to get their life back. By facing psychosis they experienced gains in different aspects of life as their symptoms improved and they re-engaged in activities and relationships. Such functional and social recovery following FEP was highlighted in other qualitative research $[7,21]$.

A few participants attempted to restore their life by escaping from or avoiding the presence and effect of psychosis. Avoidance was akin to a sealing-over recovery style [52] where people distanced themselves from psychosis because they considered it discordant with their lives. This has been associated with lower resilience during adaptation and less engagement with services [53]. Dunkley and Bates [21] deemed acceptance, active involvement in recovery, and social interaction to be more adaptive coping strategies compared to avoidance. Several participants in this research expressed their acceptance of both the detrimental and beneficial aspects of psychosis at different points during their adjustment. This was associated with integrative styles of recovery [52] where psychosis was acknowledged and integrated into one's identity and life. This recovery style was associated with good adjustment [18] and improved outcomes [54]. Participants tended to change between recovery styles as has been identified in earlier research [54].

Aspects of growth resonated in participants' accounts of their adaptation. This research substantiated that engagement with the pain of trauma was required for participants to develop a coherent explanation of FEP and to experience growth $[20,55,56]$. The considerable impact of FEP caused participants to question themselves and their life and to develop new beliefs about themselves, others, and the world. Several participants developed a strengthened and more compassionate sense of self, developed new aspirations, and appreciated their life as well as their relationships more. These resonated with four out of the five domains of PTG, and was consistent with other research [21, 22]. Strengthened spiritual beliefs were uncommon in the current and latter studies. Tedeschi [57] proposed that PTG was associated with improved well-being and coping. Different participants experienced none, some, or all aspects of PTG. This was possibly because they were in different adaptation phases when PTG could be experienced as a final outcome of recovery or as a part of the recovery process [20, 47].

Amidst gains and growth was a running narrative of participants' struggles throughout adaptation to FEP. It was challenging to accept what they lost, to face psychosis, overcome ongoing hurdles, and to re-establish their identity. The difficulties that accompanied adaptation and growth concurred with other research $[21,58]$. Nevertheless, most participants demonstrated resilience to face these challenges. Lysaker, Johannesen, and Lysaker [59] suggested that beyond symptom remission and psychosocial functioning, recovery crucially involved individuals believing themselves to be capable of changing their lives. Participants' determination was strengthened by their increased coping skills and social support. Indeed, recovery from psychosis entails both taking responsibility and accepting help [49].

\section{Using Visual Methods}

The richness of the data generated was increased through the visual research method. All participants had an initial idea of what to draw, though their freedom to visually express themselves varied. In line with previous research (e.g. [36]) a minority felt anxious about being unable to draw and struggled to visually translate their thoughts. A supportive and encouraging research atmosphere alleviated their anxiety and enabled them to draw; they felt pleased with their final image and this became a meaningful source of insight. For most participants, the image inspired deeper verbal exploration into their experience. The reflective and elaborative quality of the verbal content was striking, particularly when compared with other qualitative work with younger people, and people with psychosis. It seems likely that, as well as providing an engaging and nonthreatening means of communication about a difficult topic, the medium of the 'visual interview' also facilitated 
insightful exploration of that topic. Visual methods are sometimes considered superior to verbal research because they encourage expression of emotions when these may be difficult to articulate $[40,41,60]$. We found that the visual and verbal methods constantly strengthened each other, as other authors have highlighted [29, 37, 45]. When the images enabled participants to explore their experience verbally, some chose to make adjustments to their image; when the meaning of an image was further enriched, so was the verbal narrative.

It was important to understand participants' verbal interpretation of their image in the context of their mood and circumstances on the day [30, 61]. Davey [62] suggested that art is experienced through a synthesis of the artist, the art, and the viewer. Indeed, a shared understanding was created between the participants, their art and the first author. The absence of either one would have weakened this process of meaning-making.

\section{Evaluation}

The data elicited a wealth of information about adaptation following FEP. External estimates of the transferability of our analysis should be based upon an appraisal of our interpretative approach, and the characteristics of our small sample. Participation was only open to those using EIS. Individuals with more adaptive experiences of psychosis, and those with a pre-existing interest in art or creativity may have been more likely to participate. Nevertheless, the recruited participants described varied experiences of adaptation across the critical period, and five had no prior interest in art. Interviews relied on retrospective self-report and any given individual account may have been skewed by fluctuations in symptoms, medication use, and difficulties with communication. Additionally, their psychological adaptation may have been influenced by other factors such as ethnic background, living circumstances, social support, and by differences in time elapsed since acute psychosis. Given this variation amongst participants, we ensured that the final themes were derived from all participants, to strengthen the internal representativeness of our analysis. We sought to enhance credibility through triangulation of data collection (through the use of drawings as an adjunct to the interviews) and analysis (all four authors' perspectives contributed to this). The cross-sectional design of this research prevented identification of whether growth was actually sustained over time, or associated with functional gains. It is worth also bearing in mind Maercker and Zoellner's [63] suggestion that growth can be illusory as individuals may exaggerate their growth experience to protect themselves from pain.

\section{Clinical and Research Implications}

Participants' narratives in this research highlight the crucial role of services in supporting individuals' adaptation to FEP. Individuals should be encouraged to find a balance between embracing their support networks and becoming active agents in their adaptation, as they have to deal with both losses and gains following FEP. Awareness of growth amongst clinicians is important. This is especially true for individuals more traumatised by FEP, because degree of trauma is positively correlated with PTG [23]. Longitudinal studies are needed to understand the sustainability of PTG and its impact on individuals' quality of life and well-being. Such research can indicate how adaptation changes over time for people with FEP and whether PTG results in positive adaptation. Exploration of the impact of cultural and other sociodemographic factors on the experience of adaptation may additionally be warranted in future research.

Frankl [51] proposed that an essential aspect to finding meaning in life was accepting that suffering was an unavoidable part of it. The current research shows that pain is still present amidst the gains and growth of adaptation. Buck et al. [58] and Dunkley and Bates [21] encourage professionals to be aware of this and to support service users through both the challenges and gains of recovery. Accepting the inevitability of pain can enable individuals to work towards a meaningful and valued life [64].

Participants' appreciation for their family also highlights their role in adaptation. Family intervention is a recommended treatment for psychosis [65], through which families can understand what adaptation is like and how to support individuals through it. Ongoing service emphasis on family interventions and family involvement could strengthen individuals' adjustment [66] and growth experiences [23], besides preventing disengagement from services [67].

Qualitative research using drawings in mental health remains limited to a few studies $[29,37,60,68,69]$. Its value is evident through this research and we encourage researchers to utilise creative multi-method research with people with psychosis and other populations. Visual research methods can enable service users to express and process their experience and allow professionals a deeper verbal and visual immersion into participants' world, which can inform clinical practice. Clinicians may also consider the integration of visual methods as part of mental health assessments. The initial phases of involvement with services can be a stressful and confusing period. Flexibility and creativity of assessment methods can enable individuals' engagement as well as their expression of potentially acute and traumatic psychotic experiences, and the impact of this. Furthermore, drawings created by participants may provide insight into their current emotional, cognitive, and 
imagery based difficulties, which can guide clinicians in what support is offered.

\section{Conclusion}

The experiences of adapting to FEP were brought alive through the powerful and vivid meanings in participants' images. Adaptation involves a complex interplay of emotional pain, challenges, benefits, and psychological growth, as individuals re-engage with life, others, and themselves. Participants' verbal and visual narratives illuminate the internal strength required to adapt to FEP, together with the crucial role that services and significant others play in nurturing individuals on their path of adaptation and selfdiscovery. Visual research methods emerge as a rich source of meaning which can be beneficial for service users, researchers, and clinicians.

Acknowledgements We thank all the participants for their time and participation in this research.

Funding There are no relevant funding sources in relation to this manuscript. The first author has full access to all the data in the study and had final responsibility for the decision to submit for publication.

\section{Compliance with ethical standards}

Conflict of interest The authors declare that they have no conflict of interest.

Open Access This article is distributed under the terms of the Creative Commons Attribution 4.0 International License (http://creative commons.org/licenses/by/4.0/), which permits unrestricted use, distribution, and reproduction in any medium, provided you give appropriate credit to the original author(s) and the source, provide a link to the Creative Commons license, and indicate if changes were made.

\section{Appendix}

Table 2 Image analysis frameworks (Boden \& Eatough [29])

Framework for the analysis of the drawings

1. Contents: Describe each of the distinct elements of the image

2. Composition: How are the elements spatially laid out on the page? Are they sparse or dense, are there areas of blank page, do the elements overlap? Is there a sense of repetition, 'rhyme' or pattern?

3. Balance: How do elements interplay? Is there a sense of equilibrium or disequilibrium? Is there symmetry or pattern?

4. Geometry: What shapes are used? How do these interplay together?

5. Materials: Which material has been used for each element?

6. Texture: What are the textural characteristics of each element?
Table 2 continued

7. Colour: How have hue (colour), saturation (vividness) and value (lightness/darkness) been used?

8. Depth/Perspective: What spatial depth and perspective has been created through space and colour?

9. Temporality/Dynamism: Is there a sense of rhythm or movement? Does the image suggest a snapshot, continuity or duration?

10. Focus: What is the visual focus of the image? What is your eye drawn to?

11. Expressive content/Empathic reaction: What is the emotional tone of the image? What feelings does the seer have in response (bodily, emotional, memories, images)?

12. Signs/Symbolism: Are there any overt symbols or cultural references included?

13. Style: Does the image 'shout' or is it 'quiet'? Does the drawing seem to imitate or reflect a particular trend or style e.g. cartoonish, child-like, modern, romantic, pop-art etc. What might this choice have meant?

14. Text: Has any text been included, for example a title? Where has this been placed? In what way has it been included? What style, font, capitalisation etc. is used?

15. Distraction/Noise: Do any elements draw your attention away from the main focus? Is there a sense of confusion or a lack of clarity in the image?

Framework for the analysis of the production of the image

1. Speed: How quickly or slowly was the image produced? Did the participant spend significantly longer on particular elements compared to others?

2. Pressure: How were materials used bodily? How much pressure was applied to the page?

3. Colour: How was colour chosen? With what degree of speed, decisiveness etc.?

4. Expression: What did the participants facial expressions or spoken expressions suggest about their process?

5. Mood: What was the atmosphere or tone whilst the drawing was being created?

6. Emotion: Was any particular emotion evident in the production, or discussed in the interview?

7. Gestures: Were there any notable gestures or movements during the process?

8. Absorption: Were they involved or distanced from the activity?

9. Hesitancy: Were there any false starts or pauses in the process?

\section{References}

1. American Psychiatric Association. Diagnostic and statistical manual of mental disorders: DSM-5. Washington: American Psychiatric Association; 2013.

2. World Health Organization. The ICD-10 classification of mental and behavioural disorders: clinical descriptions and diagnostic guidelines. Geneva: World Health Organization; 1992.

3. Harrison G, Croudace T, Mason P, Glazebrook C, Medley I. Predicting the long-term outcome of schizophrenia. Psychol Med. 1996;26:697-705. doi:10.1017/S0033291700037715. 
4. Birchwood M. The critical period for early intervention. In: Birchwood M, Fowler D, Jackson C, editors. Early intervention in psychosis: a guide to concepts, evidence and interventions. England: Wiley; 2000. p. 28-63.

5. Dunkley JE, Bates GW, Findlay BM. Understanding the trauma of first-episode psychosis. Early Interv Psychiatry. 2013;9:211-20. doi:10.1111/eip.12103.

6. Lam MM, Pearson V, Ng RM, Chiu CP, Law CW, Chen EY. What does recovery from psychosis mean? Perceptions of young first-episode patients. Int J Soc Psychiatry. 2011;57:580-7. doi: $10.1177 / 0020764010374418$.

7. McCarthy-Jones S, Marriott M, Knowles R, Rowse G, Thompson AR. What is psychosis? A meta-synthesis of inductive qualitative studies exploring the experience of psychosis. Psychosis. 2013;5:1-16. doi:10.1080/17522439.2011.647051.

8. Tarrier N, Khan S, Cater J, Picken A. The subjective consequences of suffering a first episode psychosis: trauma and suicide behaviour. Soc Psychiatry Psychiatr Epidemiol. 2007;42:29-35. doi:10.1007/s00127-006-0127-2.

9. Lu W, Mueser KT, Shami A, et al. Post-traumatic reactions to psychosis in people with multiple psychotic episodes. Schizophr Res. 2011;127:66-75. doi:10.1016/j.schres.2011.01.006.

10. Riedesser P. Psychosis as a traumatic event. In: Burgin D, Meng $\mathrm{H}$, editors. Childhood and adolescent psychosis. Switzerland: Karger; 2004. p. 61-6.

11. Slade M, Amering M, Oades L. Recovery: an international perspective. Epidemiol Psichiatr Soc. 2008;17:128-37.

12. Frese FJ, Knight EL, Saks E. Recovery from schizophrenia: with views of psychiatrists, psychologists, and others diagnosed with this disorder. Schizophr Bull. 2009;35:370-80. doi:10.1093/ schbul/sbn 175 .

13. McGorry PD. The concept of recovery and secondary prevention in psychotic disorders. Aust N Z J Psychiatry. 1992;26:3-17.

14. Pitt L, Kilbride M, Nothard S, Welford M, Morisson AP. Researching recovery from psychosis: a user-led project. Psychiatr Bull. 2007;31:55-60. doi:10.1192/pb.bp.105.008532.

15. Slade M. 100 ways to support recovery: a guide for mental health professionals. Rethink recovery series. 2009; 1:1-32. http://www. mentalhealthrecovery.com/recovery-resources/documents/100_ ways_to_support_recovery1.pdf.

16. Anthony WA. Recovery from mental illness: the guiding vision of the mental health service system in the 1990s. Psychosoc Rehabil J. 1993;16:521-38.

17. Windell D, Norman R, Malla AK. The Personal meaning of recovery among individuals treated for a first episode of psychosis. Psychiatr Serv. 2012;63:548-53. doi:10.1176/appi.ps.201100424.

18. Jackson C, Iqbal Z. Psychological adjustment to early psychosis. In: Birchwood M, Fowler D, Jackson C, editors. Early intervention in psychosis: a guide to concepts, evidence and interventions. Chichester: Wiley; 2000. p. 64-100.

19. Janoff-Bullman R. Shattered assumptions. Towards a new psychology of trauma. New York: Free Press; 1992.

20. Calhoun LG, Tedeschi RG. The foundations of posttraumatic growth: new considerations. Psychol Inq. 2004;15:93-102.

21. Dunkley JE, Bates GW. Recovery and adaptation after first-episode psychosis: the relevance of posttraumatic growth. Psychosis. 2015;7:130-40. doi:10.1080/17522439.2014.936027.

22. Dunkley JE, Bates GW, Foulds M, Fitzgerald P. Understanding adaptation to first-episode psychosis: the relevance of trauma and posttraumatic growth. Australasian J Disaster Trauma Stud. 2007;1. http://www.massey.ac.nz/ trauma/issues/previous. shtml\#2007-1.

23. Linley PA, Joseph S. Positive change following trauma and adversity: a review. J Trauma Stress. 2004;17:11-21. doi:10. 1023/B:JOTS.0000014671.27856.7e.
24. Pietruch M, Jobson L. Posttraumatic growth and recovery in people with first episode psychosis: an investigation into the role of self-disclosure. Psychosis. 2012;4:213-23. doi:10.1080/ 17522439.2011 .608434$.

25. Department of Health. No health without mental health: a crossgovernment mental health outcomes strategy for people of all ages. London: Department of Health; 2011.

26. Spencer E, Birchwood M, McGovern D. Management of firstepisode psychosis. Adv Psychiatr Treat. 2001;7:133-42.

27. Morrison AP, Beck AT, Glenworth D, Dunn H, Reid GS, Larkin $\mathrm{W}$, et al. Imagery and psychotic symptoms: a preliminary investigation. Behav Res Ther. 2002;40:1053-62.

28. Smith J, Osborn M. Interpretive phenomenological analysis. In: Smith JA, editor. Qualitative psychology: a practical guide to research methods. London: Sage; 2003. p. 51-80.

29. Boden Z, Eatough V. Understanding more fully: a multimodal hermeneutic-phenomenological approach. Qual Res Psychol. 2014:11:160-77. doi:10.1080/14780887.2013.853854.

30. Mitchell C, Theron L, Stuart J, Smith A, Campbell Z. Drawings as research method. In: Theron L, Mitchell C, Smith A, editors. Picturing research: drawing as visual methodology. Rotterdam: Sense Publishers; 2011. p. 1-16.

31. Sandhu A, Ives J, Birchwood M, Upthegrove R. The subjective experience and phenomenology of depression following first episode psychosis: a qualitative study using photo-elicitation. J Affect Disord. 2013;149:166-74. doi:10.1016/j.jad.2013.01.018.

32. Patterson S, Crawford M, Ainsworth E, Waller D. Art therapy for people diagnosed with schizophrenia: therapists views about what changes, how and for whom. Int J Art Ther. 2011;16:70-80. doi:10.1080/17454832.2011.604038.

33. Patterson S, Debate J, Anju S, Waller D, Crawford MJ. Provision and practice of art therapy for people with psychosis: results of a national survey. JMH. 2011;20:328-35. doi:10.3109/09638237. 2011.556163.

34. Schaverien J, Killick K. Art Psychotherapy and Psychosis. London: Routledge; 1997.

35. Wood C. The history of art therapy and psychosis 1938-95. In: Killick K, Schaverien J, editors. Art, psychotherapy and psychosis. London: Routledge; 1997. p. 144-75.

36. Guillemin M. Understanding illness: using drawings as a research method. Qual Health Res. 2004;14:272-89. doi:10.1177/ 1049732303260445.

37. Shinebourne P, Smith JA. Images of addiction and recovery: an interpretative phenomenological analysis of the experience of addiction and recovery as expressed in visual images. Drugs. 2011;18:313-22. doi:10.3109/09687637.2010.514621.

38. Lieberman J, Jody D, Geisler S, Alvir J, Loebel A, Szymanski S, et al. Time course and biologic correlates of treatment response in first-episode schizophrenia. Arch Gen Psychiatry. 1993;50(5):369-76. doi:10.1001/archpsyc.1993.01820170047006.

39. Rose G. Visual methodologies. London: Sage; 2001.

40. Bagnoli A. Beyond the standard interview: the use of graphic elicitation and arts-based methods. Qual Res. 2009;9:547-70. doi:10.1177/1468794109343625.

41. Kearney KS, Hyle AE. Drawing out emotions: the use of participant-produced drawings in qualitative inquiry. Qual Res. 2004;4:361-82. doi:10.1177/1468794104047234.

42. Rose G. Visual methodologies: an introduction to the interpretation of visual materials. 2nd ed. London: Sage; 2007.

43. Smith JA, Flowers P, Larkin M. Interpretative phenomenological analysis: theory, method, research. London: Sage; 2009.

44. Larkin M, Thompson A. Interpretative phenomenological analysis. In: Thompson A, Harper D, editors. Qualitative research methods in mental health and psychotherapy: a guide for students and practitioners. Oxford: Wiley; 2012. p. 99-116. 
45. Kirova A, Emme M. Using photography as a means of phenomenological seeing: "Doing phenomenology" with immigrant children. IPJP. 2006;6:1-12.

46. Perry BM, Taylor D, Shaw SK. 'You've got to have a positive state of mind': an interpretative phenomenological analysis of hope and first episode psychosis. JMH. 2007;16:781-93. doi:10. 1080/09638230701496360.

47. Zoellner T, Maercker A. Posttraumatic growth in clinical psychology: a critical review and introduction of a two component model. Clin Psychol Rev. 2006;26:626-53. doi:10.1016/j.cpr.2006.01.008.

48. Hirschfeld R, Smith J, Trower P, Griffin C. What do psychotic experiences mean for young men? A qualitative investigation. Psychol Psychother. 2005;78:249-70. doi:10.1348/147608305X25865.

49. Bonney S, Stickley T. Recovery and mental health: a review of the british literature. $J$ Psychiatr Ment Health Nurs. 2008;15:140-53. doi:10.1111/j.1365-2850.2007.01185.x.

50. Stewart L, Wheeler K. Occupation for recovery. Occup Therapy News. 2005;13:20.

51. Frankl VE. Man's search for meaning: the classic tribute to hope from the Holocaust, 5th edn. Reading: Rider; 2004.

52. McGlashan TH, Docherty J, Siris S. Integrative and sealing-over recoveries from schizophrenia: distinguishing case studies. Psychiatry. 1976;39:325-38.

53. Tait L, Birchwood M, Trower P. Adapting to the challenge of psychosis: personal resilience and the use of sealing-over (avoidant) coping strategies. Br J Psychiatry. 2004;185:410-5. doi:10. 1192/bjp.185.5.410.

54. Thompson KN, McGorry PD, Harrigan SM. Recovery style and outcome in first-episode psychosis. Schizophr Res. 2003;62:31-6. doi:10.1016/S0920-9964(02)00428-0.

55. Kashdan TB, Kane JQ. Post-traumatic distress and the presence of post-traumatic growth and meaning in life: Experiential avoidance as a moderator. Pers Indiv Differ. 2011;50:84-9. doi:10.1016/j.paid.2010.08.028.

56. Tedeschi RG, Calhoun LG. Posttraumatic growth: conceptual foundations and empirical evidence. Psychol Inq. 2004;15:1-18.

57. Tedeschi R. Violence transformed: Posttraumatic growth in survivors and their societies. Aggress Violent Behav. 1999;4:319-41. doi:10.1016/S1359-1789(98)00005-6.

58. Buck KD, Roe D, Yanos $\mathrm{P}$, et al. Challenges to assisting the recovery of personal identity and wellness for persons with serious mental illness: considerations for mental health professionals. Psychosis. 2014;5:134-43. doi:10.1080/17522439.2012. 699544.

59. Lysaker PH, Johannesen JK, Lysaker JT. Schizophrenia and the experience of intersubjectivity as threat. Phenomenol Cogn Sci. 2005;4:335-52. doi:10.1007/s11097-005-4067-1.

60. Gillies V, Harden A, Johnson K, Reavey P, Strange V, Willig C. Painting pictures of embodied experience: the use of nonverbal data production for the study of embodiment. Qual Res Psychol. 2005;2:199-212. doi:10.1191/1478088705qp038oa.

61. Pink S. Doing visual ethnography: images, media and representation in research. London: Sage Publications Ltd; 2001.

62. Davey N. The hermeneutics of seeing. In: Heywood I, Sandywell B, editors. Interpreting visual culture. New York: Routledge; 1999. p. 3-30.

63. Maercker A, Zoellner T. The Janus face of self-perceived growth: toward a two-component model of posttraumatic growth. Psychol Inq. 2004;15:41-8.

64. Hayes SC, Smith S. Get out of your mind and into your life: the new acceptance and commitment therapy. Oakland: New Harbinger; 2005.

65. National Institute for Health and Care Excellence. CG178 Psychosis and schizophrenia in adults: treatment and management. London: National Institute for Health and Care Excellence; 2014.

66. Boydell KM, Stasiulis E, Volpe T, Gladstone B. A descriptive review of qualitative studies in first episode psychosis. Early Interv Psychiatry. 2010;4:7-24. doi:10.1111/j.1751-7893.2009. 00154.x.

67. Doyle R, Turner N, Fanning F, et al. First-episode psychosis and disengagement from treatment: a systematic review. Psych Serv. 2014;65:603-11. doi:10.1176/appi.ps.201200570.

68. Guillemin M, Westall C. Gaining insight into women's knowing of postnatal depression using drawings. In: Liamputtong P, Rumbold J, editors. Knowing differently: arts-based and collaborative research methods. New York: Nova Science Publishers; 2009. p. 121-39.

69. Robbins BD. Being joyful: an empirical-phenomenological study. In: Fischer CT, editor. Qualitative research methods for psychologists: case demonstrations. New York: The Guildford Press; 2003. 